\title{
Los inicios de la enseñanza de la litetratura rusa en España y su proyección actual: la estilística del texto
}

\author{
Aída Fernández Bueno \\ Universidad Complutense de Madrid (España) \\ afbueno@filol.ucm.es
}

Recibido: Diciembre de 2011

Aceptado: Enero de 2012

\section{Resumen}

Los inicios de los estudios de Lengua y Literatura rusas en España, concretamente en la antigua Universidad Central, deben mucho a figuras poco conocidas, pero que fueron determinantes para su posterior evolución y proyección actual. El interés por la literatura y cultura rusas, amén de su lengua, se fue consolidando y arraigando en los estudios universitarios. La especialización propia de éstos hizo posible la introducción de nuevos principios teóricos y metodológicos -como la estilística del texto rusa- en la enseñanza y estudio de la literatura rusa.

Palabras clave: Literatura rusa, estilística del texto, composición, autor, lector.

The beginnings of Russian literature teaching in Spain and current projection: text stylistics

\begin{abstract}
The first studies in Spain of Russian Language and Literature, concretly in the former Central University, owe much to little-known figures, but which were crucial for further developments and projections. The interest in Russian literature and culture, in addition to their language, was consolidated and ingrained in the studies in the university. Their own specialization made possible the introduction of new theoretical and methodological principles -as the Russian Text stylistic- in the teaching and study of Russian literature.
\end{abstract}

Key words: Russian literature, text stylistic, composition, , author, reader.

SUMARIO: 1. Introducción; 2.La estilística del texto; 3. Un ejemplo: Дурочка de Иван Бунин; 4. Epílogo. 


\section{Introducción}

Asistimos al relanzamiento del interés por la lengua rusa y lo ruso en muy diferentes esferas: social, económica, política, comercial y, por supuesto, cultural y académica. Prueba de ello es el apoyo de las instituciones promoviendo un intercambio al más alto nivel, que redunde directamente en la base, en el público en general, y posibilite un mayor conocimiento de los respectivos universos socio-culturales: ruso y español ${ }^{1}$. Ese relanzamiento es motivo de enhorabuena, pero debemos contextualizar ese éxito y sobre todo, ahondar en sus raíces para proyectar futuras líneas de trabajo.

El intercambio humano necesita, desde el primer peldaño y en todas las áreas, el conocimiento por ambas partes de las respectivas lenguas: rusa y española. En Rusia siempre ha habido un interés por la lengua española y la apertura de la sede del Instituto Cervantes ${ }^{2}$ en Moscú no hizo sino oficializar y canalizar ese intercambio cultural ya existente. En España dos acontecimientos, de un pasado aún reciente y compartido, influyeron en la evolución del estudio de la lengua rusa: la revolución de octubre y la guerra civil española.

El camino que ahora recorremos debe mucho a los que ya no se encuentran entre nosotros, pero sin los cuales, sin su esfuerzo, lucha, empeño e ilusión la situación que ahora vivimos - por lo que respecta a la incidencia de los estudios de lengua y literatura rusas en nuestro sistema educativo-, sería diferente. Mi recuerdo se dirige a Constant Brusiloff ${ }^{3}$, personaje enigmático, nacido en San Petersburgo y que recalaría en España en los años 30 desde donde finalmente emigraría a América. Con él comenzó la andadura de los Estudios de Ruso en la Facultad de Filosofía y Letras de los años 30 de la por aquel entonces Universidad Central. Reivindico su figura como precursor y destaco su carácter innovador por el método que utilizó y la forma como lo llevó a efecto. En aquella Facultad de Morente, el profesor-lector Constant Brusiloff fue el docente que aplicó la metodología de trabajo más moderna en la enseñanza de una lengua extranjera y su literatura 4 .

Después de aquel curso de 1935-36 imperó un largo silencio y son muy pocos los que por aquel entonces en España se interesaban por el estudio de la lengua y cultura rusas. Es justo que en este momento reconozcamos a Julio Calonge (FERNÁNDEZ BUENO 2010: 141-147) como un gran estudioso, en la sombra, del universo lingüístico y cultural ruso, que publicó en 1969 Transcripción del ruso al español (CALONGE 1969).

\footnotetext{
1 Un claro ejemplo de esta colaboración a nivel estatal es la celebración en el año 2011 del Año Dual de Rusia en España y de España en Rusia. Instituciones como la Universidad Complutense de Madrid o la Universidad de Granada han organizado actividades académicas para reforzar y ampliar el intercambio científico como, por ejemplo: Seminario Internacional «Rusia y España, una fascinación mutua», UCM, octubre de 2011; Foro Internacional «Rusia y España: tendencias de convergencia y perspectivas de cooperación», Universidad de Granada, septiembre de 2011 .

2 La sede del Instituto Cervantes en Moscú fue inaugurada en el año 2002 por el Príncipe de Asturias.

${ }^{3}$ Los documentos estudiados, y las publicaciones surgidas a raíz de ellos, —AIZPURU (2009b: 396-399) y AIZPURU (2009a) — reproducen el apellido Brusiloff siguiendo el sistema de trasliteración al uso en las primeras décadas del siglo XX. Según las normas actuales de trasliteración del ruso al español deberíamos citar: Brusílov (véase, CALONGE 1969).

${ }^{4}$ AIZPURU (2009b: 396-399). Véase también AIZPURU (2009a) en donde se trata la figura de Constant Brusíloff desde un punto de vista histórico y socio-político.
} 
En los años 80 Liudmila Kaida, profesora de la Universidad Lomonósov de Moscú, se incorpora a la Facultad de Filología de la UCM para impartir docencia en Doctorado y en los estudios de Filología Eslava, además de formar a un grupo de especialistas. Aquella experiencia formativa propició que, con el transcurso de los años, proclamáramos la necesidad de que el modelo para la enseñanza de la literatura rusa en el ámbito universitario se distanciara del tradicional y se aproximara al de la estilística del texto rusa. Su carácter práctico, innovador y motivador, algo fundamental en un momento de diversificación de titulaciones universitarias en donde los alumnos no se inclinan, precisamente, por las de perfil humanístico, eran los principales activos.

\section{La estilística del texto}

¿Por qué la estilística del texto rusa? Desde nuestra posición de docentes percibíamos unas carencias en el sistema y en el método que se concretaban, básicamente, en la sobrevaloración del aspecto teórico en el estudio de la literatura en detrimento de su aplicación a los textos; y la falta de interés por la lectura y la literatura, con la consiguiente disminución del número de alumnos en estos estudios. En definitiva, abundaba la perspectiva más tradicional en el estudio y la enseñanza de la literatura. Quizá esa situación propició el que uno de los aspectos más relevantes, diferenciadores y aplaudidos de la teoría literaria rusa, en su aplicación en el aula, fuera, paradójicamente, su carácter eminentemente práctico.

Los planteamientos teóricos y principios metodológicos de la estilística del texto eran poco conocidos en nuestro medio académico y universitario ya que el eco de la difusión del método formal en nuestro país fue tan prolongado en el tiempo, que solapó los desarrollos teóricos posteriores. No obstante, sí había lingüistas — como F. Lázaro Carreter ${ }^{5}$ - , que mostraron una actitud más abierta reconociendo, que los fundamentos teóricos y las posibilidades de aplicación de la estilística funcional merecían ser conocidas entre nosotros. Posteriormente aumentaría el número de investigadores ${ }^{6}$ interesados por los trabajos de la escuela filológica rusa que, en buena medida, coincidían en la misma reflexión final: la necesidad de traducir estas obras para hacerlas visibles y accesibles al lector especialista español ${ }^{7}$. La aparición del libro de L. Kaida Estilística funcional rusa a mediados de los 80 representó un momento clave en la divulgación de los trabajos sobre estilística rusa en el ámbito hispánico.

La estilística rusa tiene una larga tradición en los estudios filológicos, que se remonta hasta Lomonósov. Se ha desarrollado en el marco del funcionalismo y su principio rector proclama que cada elemento tiene una función y eso justifica su presencia. La estilística del texto se formula a raíz de la publicación de la monografía de V. Odintsov Стилистика текста ${ }^{8}$ en 1980. N. Bolotnova otorga a la estilística

\footnotetext{
5 Véase LÁZARO CARRETER en KAIDA (1986: 11-13).

${ }^{6}$ Me refiero a los trabajos de GARRIDO GALLARDO (1974, 1994), PAZ GAGO (1993), RODRÍGUEZ PEQUEÑO (1995) y VÁZQUEZ MEDEL (1988).

${ }^{7}$ Más recientemente cabe añadir el trabajo de GÓMEZ ALONSO (2002: 59-63) quien dedica un capítulo a la Estilística Funcional rusa.

8 ОДИНЦОВ (1980). Esta monografía se ha publicado de nuevo en 2004 en una edición a cargo de А. И. Горшков (КАЙДА 2005: 37).
} 
del texto un estatuto científico y la define del siguiente modo: “Стилистика Текста - область филологического знания, которая исследует текст в стилистическом аспекте [...]" (La estilística del texto es una disciplina filológica que se ocupa del texto en su aspecto estilístico [...]) (БОЛОТНОВА (2009: 217).

La estilística del texto se propone, a través del método de la descodificación ${ }^{9}$ (методика декодирования), descubrir los procedimientos que ayudan al lector a comprender de un modo más profundo un texto y la idea que el autor ha encarnado en él. En palabras de Kaida, la descodificación implica: "el descubrimiento — desde el punto de vista del lector- del significado real de las unidades lingüísticas que reflejan la idea del autor del texto" (KAIDA (1998: 17).

La composición es la principal unidad de la estilística del texto además de “главный объект внимания - композиция [в тексте]" (el principal objeto de atención en el texto) (КАЙДА (2005: 52) y su estudio supone una nueva etapa de la investigación que puede aplicarse a cualquier tipo de texto, no sólo literario. En ese nivel composicional "se muestra el significado real de las estructuras sintácticas, de los componentes de la composición (título, comienzo, final, etc.) como resultado de su funcionamiento en el texto" (KAIDA (1998: 17).

Para nosotros resultan especialmente llamativos dos de sus principios metodológicos porque contrastan de pleno con nuestras prácticas de análisis literario más difundidas y casi hegemónicas durante un tiempo. El primero se refiere a la consideración del texto como un todo. El principio de análisis implica partir desde el texto. La afirmación "el texto es un sistema" (текст - система) se convierte en un axioma que conlleva la consideración del texto como una unidad de contenido y forma, y esto contrasta con nuestra visión del texto - más tradicional, extendida y fragmentada - como estructura. Además, en segundo lugar, y estrechamente vinculado a lo anterior, la descodificación se dirige desde el todo hacia los componentes (от целого к составным частям), pero siempre guardando la visión de conjunto. Al texto, como sistema cerrado, solo se puede acceder a través de una lectura seria, rigurosa y profesional que descienda a las profundidades del texto. Este tipo de lectura demanda un lector especial, y el estudiante de filología (Lenguas modernas y sus literaturas en los planes de estudio actuales) encarna ese lector especial que entiende y valora ese texto concreto como artístico, singular y original. Por todo ello consideramos imprescindible presentar y difundir estos métodos de trabajo con los textos literarios entre nuestros universitarios, porque incorporan una visión global de lo que sea literatura o el hecho literario al integrar teoría y práctica.

El problema se plantea en el momento de trasladar esa teoría a la práctica diaria en el aula. La metodología de análisis y trabajo con los textos que ofrece la estilística del texto es muy rica pero su aplicación en el aula ha de ser selectiva y necesariamente adaptada al nivel de conocimientos lingüísticos de nuestros alumnos. Es decir, tendremos que tener muy presente que se trata de estudiantes de una lengua y

\footnotetext{
${ }^{9}$ En lo sucesivo, y en relación con el término методика декодирования [método de la descodificación] y su traducción al español, emplearé el término método, incluso metodología, en vez del germanismo metódica. Metódica no es la traducción más adecuada del término ruso, cuanto más que metódica en español existe como adjetivo (metódico, -a) y no como sustantivo. Así, en lo sucesivo, me referiré al método de la descodificación. Esta posición contrasta con la mantenida en su día (FERNÁNDEZ BUENO, 1997).
} 
literatura extranjeras. En cualquier caso el punto de partida será siempre el mismo: la lectura rigurosa y reiterada del texto con el fin de comprenderlo en la variante más próxima al autor. La idea del autor se realiza a través de la selección y utilización de un determinado material léxico y mediante unos recursos lingüísticos y estilísticos (ironía, sorpresa, contraste....) y por supuesto, a través de su organización.

Una vez solucionados todos los problemas lingüísticos, un punto de atención preferente es atender a elementos clave de la composición como el título, en tanto que concentra el pensamiento del autor y es la primera representación del texto.

Por último nos pararemos en el análisis y estudio de los personajes. El autor también se manifiesta a través de ellos, en la manera como están construidos y en cómo evolucionan, incluso se convierte en un personaje más.

\section{Un ejemplo: Дурочка de Иван Бунин}

Tomemos como ejemplo el cuento de Иван Бунин Дурочка ${ }^{10}$ fechado en 1940. Debemos partir de la premisa de que el hecho literario es un acto comunicativo en el que el emisor, el autor, quiere trasmitir un mensaje - su obra en cuestión - a un receptor, en nuestro caso el lector, individualizado o general, pero siempre anónimo, desconocido. Ese mensaje literario será una ficción. Puesto que estamos hablando de literatura, los textos tienen un valor, no tanto por su función referencial, sino por su función poética. Es decir, nos interesan por su valor poético y nosotros como lectores, receptores, acudimos a los textos literarios para leer y conocer historias porque nos interesa cómo se cuentan y no tanto qué se cuenta. Ese cómo un autor narra una historia, en definitiva, cómo organiza un material lingüístico, en principio aséptico y objetivo, neutro, es el centro de lo que se considera hecho literario. Esa determinada organización que otorga el autor a un material lingüístico concreto comienza en el mismo título y se prolonga hasta el final y los personajes serán los entes de ficción encargados de dar vida a todo ese material.

En nuestro caso, el título - Дурочка (La tontita) — nos remite al personaje principal, pero el sustantivo elegido ya tiene una carga poética afectiva muy fuerte predisponiéndonos en una determinada dirección. Sin darnos cuenta el autor nos ha colocado del lado de esta joven y contemplamos con estupor lo que le ocurre, solidarizándonos inconscientemente con ella y su destino. El autor potencia e inclina aún más la balanza de su lado colocando al otro personaje protagonista, el seminarista, en relación de opuestos, como su antagonista. Bunin se sirve magistralmente del contraste como recurso literario, sencillo, pero de gran efectividad estética. El contraste, la oposición, se convierten en el principal recurso artístico-estético, en su principio constructivo, transmitiéndose a todos los elementos compositivos, por ejemplo el título, y a todo lo que rodea a los personajes: el ambiente en el que se

\footnotetext{
10 Son varias las razones por las que he seleccionado este texto para su trabajo en el aula. Por un lado se trata de un autor laureado pero no suficientemente conocido. Por otro lado el cuento, como género, y dadas sus dimensiones, es muy práctico y atractivo para trabajar en un aula de lengua y literatura extranjeras. Su longitud invita a la lectura y facilita el trabajo. El argumento y la temática que aborda el cuento es actual, aunque los ropajes con los que se reviste queden un poco trasnochados.
} 
mueven y la actitud de cada uno. La dicotomía luz-oscuridad (свет-темнота) define la realidad circundante y los universos de la tontita frente al del seminarista. Ella se mueve en espacios abiertos y luminosos mientras que los del seminarista son cerrados, cargados, asfixiantes incluso, y oscuros, como la cocina. Así, las referencias léxicas al universo de la tontita incluyen términos como: свет, речка, улица, деревня, село, mientras que las del seminarista se concentran en una sola y tétrica palabra, дом, desnaturalizada y desprovista de su matiz más profundo, cálido y privado, el hogar. Junto a estos dos campos básicos luz-oscuridad, encontramos una serie de conceptos, también dispuestos en parejas de contrarios, y asociados a uno u otro personaje: bondad-maldad (добро-злость), rabia (гнев), risas (хохот), bulliciosilencio (шум-молчание).

El tercer personaje, el niño, hijo de la tontita y del seminarista, aparece socialmente marcado como fruto y motivo de deshonra. Sin embargo el niño personifica y materializa la evolución interior que ha experimentado la madre convirtiéndose en su motivo de orgullo. La maternidad le ha restituido el valor y el honor perdidos con la violación, y quien en un primer momento aparecía como una mujer simple, una tontita (дурочка), una cocinera (кухарка), se convierte en madre (мать), en una madre que defenderá a su hijo y vivirá solo para él. En el propio título está, velada, la sorpresa, su antítesis, su negación. De ninguna manera se trata de una tonta, sino de una mujer maltratada y golpeada, pero con tanto amor y coraje, que se coloca por encima de todos los formalismos y convencionalismos, por encima del resto de los personajes, muy especialmente del seminarista, de su familia y conocidos. Los rasgos de su carácter la singularizan y Bunin dirá de ella, al final y como colofón, "но была неутомима" (pero era invencible).

El personaje del niño también está construido sobre la base del contraste que se desliza entre la imagen que sugiere por su condición de niño pequeño: ternura, amor, fragilidad, indefensión, y lo que siente su padre por él, rabia у оdio: “дьяконов сын, побагровев, кинулся на него подобно тигру и с такой силой швырнул вон из комнаты, что мальчик кубарем покатился в прихожую" (el hijo de los diáconos, poniéndose rojo, se lanzó sobre él como un tigre y con tal fuerza lo arrojó fuera de la habitación, que el niño fue rodando hasta la antesala). Esa dicotomía amor-odio se refleja en su aspecto físico: “он был урод" (era horrible) pero al mismo tiempo toda esa carga negativa, despectiva, se deshace inmediatamente cuando el autor, justo al final, apostilla: "Но когда он улыбался, он был очень мил" (pero cuando sonreía era muy agradable). Estas dos intervenciones del autor para con sus dos personajes más queridos, los individualiza y ensalza, al mismo tiempo que establece un paralelismo final entre la suerte de madre e hijo aunándolos en la desgracia, y también en el renacer.

\section{Epílogo}

En Rusia la estilística del texto se desarrolla a un ritmo totalmente diferente y cosecha un gran éxito y difusión en los planes de estudio de varias disciplinas humanísticas. Esa perspectiva y proyección de futuro de la estilística del texto, su ver- 
tiente y aplicación didácticas, cierra la línea temporal o la cronología interna de la estilística, desde sus orígenes, su realidad actual y su proyección futura.

Es cierto que desde aquí, desde esta orilla ${ }^{11}$, aún queda mucho por hacer con vistas a promover un mejor conocimiento de los últimos trabajos de lingüistas e investigadores literarios rusos. Los pasos que se dan para ahondar en el conocimiento teórico de la estilística del texto y sus aplicaciones para favorecer su difusión en el ámbito científico y académico español son aún cortos. Esperamos en adelante avanzar a pasos ya más firmes y acelerados.

\section{Referencias bibliográficas}

AIZPURU, M. (2009a): El informe Brusiloff. La Guerra Civil de 1936 en el Frente Norte vista por un traductor ruso, Alberdania, Guipúzcoa.

AIZPURU, M., FERNÁNDEZ BUENO, A., (2009b): "Los estudios de Filología Moderna. Ruso" en La Facultad de Filosofia y Letras de Madrid en la Segunda República. Arquitectura y Universidad durante los años 30, Sociedad Estatal de Conmemoraciones Culturales, Madrid, pp. 396-399.

CALONGE RUÍZ, J. (1969): Transcripción del ruso al español, Gredos, Madrid.

CALONGE RUÍZ, J. (2005): Estudios de lingüística, filología e historia, Gredos, Madrid. Dispuesto para la imprenta por J. Polo. Prólogo de A. Bernabé.

FERNÁNDEZ BUENO, A. (1997): La obra literaria: evolución teórica y metodológica, UCM, Madrid. Tesis doctoral.

FERNÁNDEZ BUENO, A. (2002): "La aportación de la estilística funcional rusa a la didáctica de la literatura en España. La lectura profesional: método para crear lectores" en España y el mundo eslavo: Relaciones culturales, literarias y lingüísticas, Gram Ediciones, Madrid.

FERNÁNDEZ BUENO, A. (2003): "El análisis estilístico aplicado a la enseñanza de la literatura rusa. Un enfoque práctico", Eslavística Complutense, vol. 3, p.131-147.

FERNÁNDEZ BUENO, A. (2010): "Julio Calonge y su trabajo como rusista"en Revista Española de Lingüística, 40/2, p.141-147.

GARRIDO GALLARDO, M. A. (1974): "Presente y futuro de la Estilística" en Revista Española de Lingüistica, $\mathrm{n}^{\circ} 4$, p. 207-218.

GARRIDO GALLARDO, M. A. (1994): La musa de la retórica, CSIC, Madrid.

GARRIDO GALLARDO, M. A.(dir.) (2009): El lenguaje literario. Vocabulario crítico, Síntesis, Madrid.

GÓMEZ ALONSO, J. C. (2002): La estilística de Amado Alonso como una teoría del lenguaje literario, Universidad de Murcia.

KAIDA, L. G. (1986): La estilística funcional rusa. Problemas actuales, Cátedra, Madrid.

KAIDA, L. G. (1998): Filología rusa moderna. Nueva vertiente, Ediciones del Orto, Madrid.

PAZ GAGO, J. M ${ }^{\text {a }}$ (1993): La estilística, Síntesis, Madrid.

RODRÍGUEZ PEQUEÑO, M. (1995): Teoría de la literatura eslava, Síntesis, Madrid.

VÁZQUEZ MEDEL, M. (1988): Historia y crítica de la reflexión estilistica, Alfar, Sevilla. БОЛОТНОВА, Н.С. (2009): Коммуникативная стилистика текста. Словарь-тезаурус, Флинта-Наука, Москва.

\footnotetext{
11 Tomo el término de KAIDA (1998: 141) que alude a las posiciones encontradas que mantienen la escuela filológica española y rusa respecto del carácter de la estilística.
} 
БУНИНИ, И. А. (1995): “Дурочка” еn Темные аллеи, Booking International, Paris.

КАЙДА, Л.Г. (2005): Стилистика текста: от теории композиции-к декодированию, Флинта-Наука, Москва.

КАЙДА, Л.Г. (2011): Композиционная поэтика текста, Флинта-Наука, Москва.

ОДИНЦОВ, В. В. (1980) Стилистика текста, Москва. 